\title{
LE DÉVELOPPEMENT DES MODÈLES D'HABITAT POUR LES SALMONIDÉS D'EAU COURANTE ET LEUR APPLICATION À LA GESTION PISCICOLE.
}

\author{
S. BARNARD (1), R.J. WYATT (1), N.J. MILNER (2)
}

(1) WRc plc, Henley Road, Medmenham, Marlow, Bucks., SL7 2HD, United Kingdom.

(2) NRA Welsh Region, Highfield, Priestley Road, Caernarfon, Gwynedd, LL55 1HR, United Kingdom.

\section{RÉSUMÉ (traduit par les éditeurs)}

Le texte décrit brièvement le développement de HABSCORE, une méthode d'évaluation de l'habitat basée sur une série de modèles statistiques empiriques qui relient l'abondance des salmonidés aux variables d'habitat observées. Des données sur les poissons et l'habitat de 602 sites de référence du Pays de Galles et de Grande-Bretagne ont été utilisées pour développer des modèles de prédiction des populations de salmonidés. Sur ces sites, 130 variables indépendantes ont été relevées à partir desquelles 5 modèles de régression, prédisant la taille des populations salmonicoles, ont été produits. Ces modèles [pour les saumons $\mathrm{O}_{+}>\mathrm{O}_{+}$, les truites $\mathrm{O}_{+},>\mathrm{O}+(<20 \mathrm{~cm})$ et $>0+(>20 \mathrm{~cm})$ ] rendent compte de 28,7 à $46,2 \%$ de la variance totale des densités de population observées dans les données de base. Une partition des variances indique que les modèles prennent en compte 45,1 à $86,7 \%$ de la variation spatiale totale. L'erreur associée aux mesures des variables d'habitat ne représente que moins de $1,1 \%$ de la variance totale dans les 5 modèles. La qualité de ces modèles est brièvement discutée. Les sorties des modèles et les applications potentielles de HABSCORE sont décrites.

Mots-clés : habitat, gestion de la pêche, modèle, prédiction, salmonidés.

\section{THE DEVELOPMENT OF HABITAT MODELS FOR STREAM SALMONIDS, AND THEIR APPLICATION TO FISHERIES MANAGEMENT.}

\section{SUMMARY}

The paper briefly describes the development of HABSCORE, a salmonid habitat assessment technique based on a series of empirical statistical models which relate salmonid abundance to observed habitat variables.

Fisheries and habitat data for 602 notionally pristine sites throughout England and Wales were used in the development of salmonid population prediction models. These sites provided a total of 130 independent variables from which five regression models, predicting salmonid population size, were produced. These models (for $0^{+}$salmon, $>0^{+}$salmon, $0^{+}$ trout, $>0^{+}[<20 \mathrm{~cm}]$ trout and $>0^{+}[>20 \mathrm{~cm}]$ trout) explained between $28.7 \%$ and $46.2 \%$ of the total variance in population densities observed in the raw data.

Partitioning of the variances within the raw data suggested that the models account for between $45.1 \%$ and $86.7 \%$ of the total spatial variation. Error associated with the measurement of the habitat variables used accounted for $\leq 1.1 \%$ of the total variance in the five models.

The quality of the models is briefly discussed. The outputs of the models, and the potential management applications of HABSCORE, are described.

Key-words : habitat, fishery management, model, prediction, salmonids. 


\section{INTRODUCTION}

The evaluation of stream habitats in terms of their suitability for different specific fish species is a practice which can be traced back some 30 years (for example, MCFADDEN and COOPER, 1962). Fisheries scientists have produced a vast array of multivariate models designed to predict standing crops of stream fish (in terms of number or biomass per unit length or area) from measurable characteristics of the stream and catchment environment. Such models cover a variety of warm- and cold-water fisheries and refer to both salmonid and non-salmonid fish species.

The potential applications of fisheries habitat models fall into the areas of enhancement, conservation and impact assessment (MILNER et al., 1985). Their potential has been demonstrated by the routine use of the salmonid fishery management tool HABSCORE (MILNER et al., 1985 ; NRA, 1991). This is a system which (in its original form) facilitated the evaluation of salmonid stream habitat in upland streams in Wales. It is currently used operationally by fisheries scientists in the Welsh Region of the National Rivers Authority (NRA), (WINSTONE, 1993).

\section{Development of the HABSCORE system}

The HABSCORE system has recently been re-developed to increase the geographical range of its potential application. A new set of empirical models, which form the basis of the latest version of HABSCORE, have been derived from a specially compiled data-set covering sites throughout England and Wales.

As with the original HABSCORE, these models permit the prediction of salmonid abundance from information on in-stream and riparian habitat features along with variables relating to large-scale catchment features. Associated computer software, which enables the models to be used to predict the expected salmonid population densities at new sites, has been produced for routine use by fisheries scientists and managers throughout the NRA.

An important feature of the HABSCORE system is that the models have been developed using data from notionally pristine sites (sites where it is believed that there are no artificial constraints to the population and where recruitment is not limiting). The derived models effectively predict the density of salmonids that would be expected under similar circumstances. Therefore, predictions from HABSCORE for new sites can be used as a standard/target against which observed fish populations can be compared; deviations being attributable to water quality impacts or limitations to recruitment.

This paper briefly describes :

- the nature of the habitat information which has been collated for the development of the HABSCORE system ;

- the results of the modelling exercises undertaken on the national database ;

- the potential uses of the resultant models.

\section{METHODS}

The features of the data which underly the development of empirical models have been assessed (FAUSCH, 1988 ; BARNARD, 1992) and through such studies it has been suggested that good quality models are usually developed from large data-sets which include a wide range of predictor (i.e. independent) variable types. When applied to data from new sites, models perform better if the general nature of such sites is similar to that of those used in the model's development. Therefore, to ensure a potentially wide applicability, models should be developed from data covering a wide range of river types (e.g. sites on a many different catchments, spread over a wide geographic scale).

Sites selected for use in the development of the HABSCORE were screened, effectively removing from the database those sites known to be subject to identifiable environmental impacts. Data were collected over a two year period (1992/3 and 1993/4) from a total of 602 sites throughout England and Wales. 


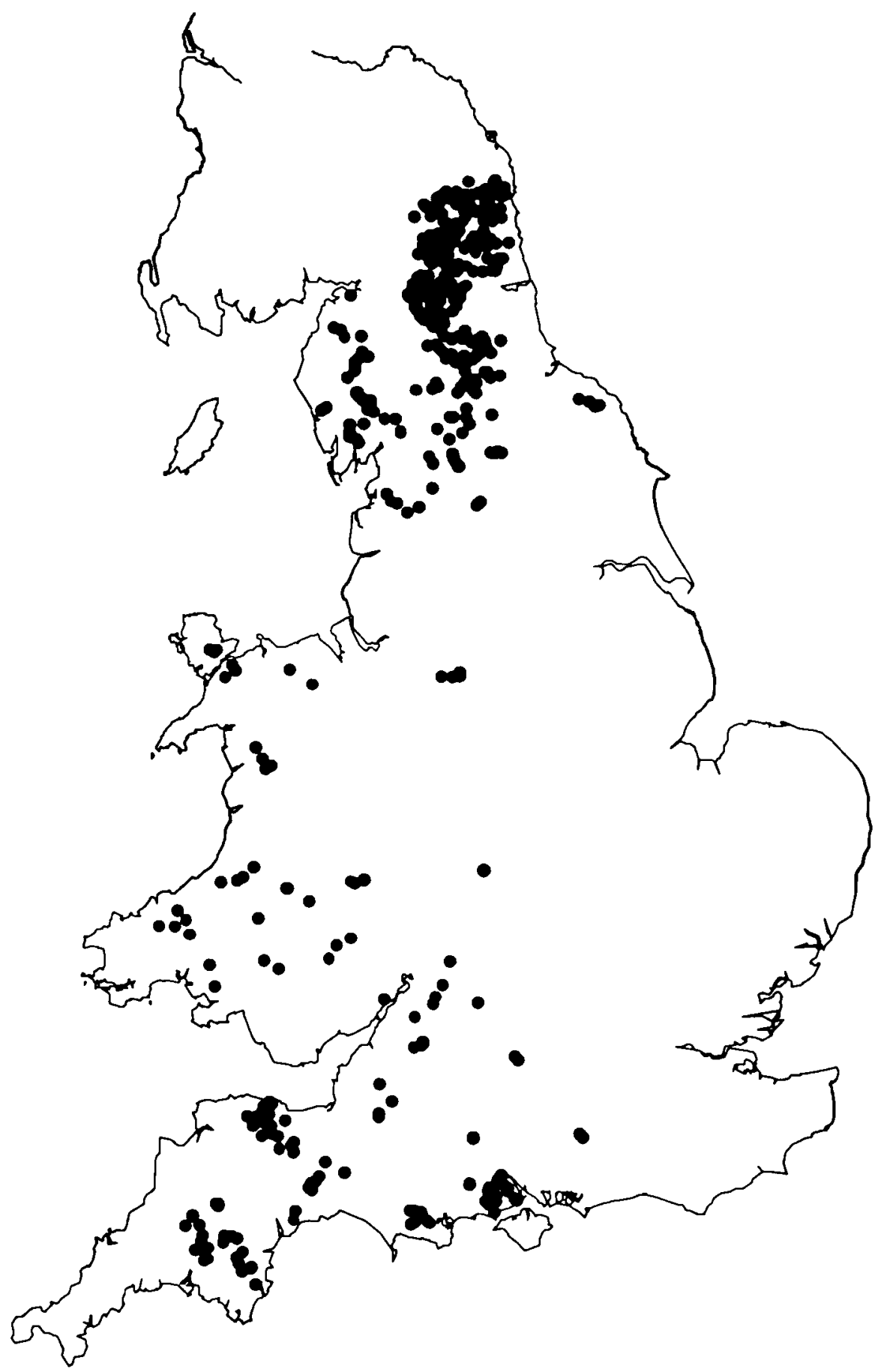

Figure 1 : Répartition géographique des sites d'étude.

Figure 1 : Geographical distribution of survey sites.

The geographical distribution of these sites is shown in Figure 1. In general, all data were collected during the summer months. In an attempt to account for any potential effects that the date of sampling may have had, the sampling day number was included as an independent variable in the modelling exercises. 
For each site, fully quantitative estimates of the salmonid population size were derived from the results of repeated electric fishing between fixed stop nets. These population estimates were obtained using the Maximum Weighted Likelihood method (CARLE and STRUB, 1978). Many of the sites had low numbers of fish present, and were surveyed using a low number of removals. As this invalidated the large sample requirements of available variance estimators, variances of removal estimates were obtained by simulation techniques.

The assessment of in-stream and riparian habitat features at each site (typically between 25 and $50 \mathrm{~m}$ in length) was carried out by means of a standardised field survey technique. Gross riparian features were recorded for the site as a whole, whilst for the detailed in-stream habitat assessment (recording the abundance of : vegetation; different categories of substrate and flow ; and potential sources of cover) the site was subdivided into a series of $10 \mathrm{~m}$ sections. Abundance estimates for the individual sections (recorded as percentage values) were subsequently weighted by section area and combined to provide an estimate of the overall percentage abundance for the site.

In addition to in-stream and riparian habitat features, a series of catchment features were also recorded - the majority of information being obtained from 1:50,000 scale Ordnance Survey maps. Initially a total of 40 independant variables were recorded for each site (Table I).

The set of independent variables used in the subsequent modelling exercises also included an additional selection of 'derived' variables, based on the joint occurence of two or more habitat variables measured at the site. A total of 90 such variables, (combinations of the various categories of substrate, flow and cover) were derived by treating percentage estimates of abundance as probabilities of occurrence, and assuming that substrate, flow and cover types were independent of each other. They included, for example, estimates of the abundance of cobble substrate overlain by shallow turbulent/broken water and of the area of gravel substrate overlain with turbulent/broken water.

Models were derived for five categories of salmonid : $0^{+}$salmon ; $>0^{+}$salmon ; $0^{+}$trout ; $>0^{+}$trout $[<20 \mathrm{~cm}]$; and $>0^{+}$trout $[>20 \mathrm{~cm}]$. Each of these models assumed lognormal error distributions. Accordingly, the dependent variable was logged, with zero values (i.e. observations with no fish) being ommitted from the analysis.

The correct way to deal with zero estimates would have been to utilise a General Linear Model, with several components of variance. However, this technique is relatively new (e.g. MCCULLAGH and NELDER, 1989) and was felt to be beyond the scope of the study. One approximate method which is sometimes used with log-models is to add a constant (usually one) to every observation. However, a zero estimate of fish may arise through sampling error at a low density (i.e. in conditions of poor habitat) or at a true zero density (i.e. in conditions of very poor habitat). To treat these two situations as the same could bias the model. Zeros were therefore omitted from the analysis. This had the effect of improving the fit of the model over the range of habitats where fish occurred, and yet enabled zero observations to be correctly predicted in sub-optimal habitat.

To account for the fact that the measurement error associated with the removal method may vary considerably between observations, and that reliable population estimates derived from good data should receive greater weight in the regression analysis, the Iterative Weighted Least Squares (IWLS) technique (POCOCK et al., 1981) was used to derive appropriate weightings for each data point. Models were derived by using forward stepwise regression of population data on habitat variables, using the IWLS methodology to refine the weightings applied during the regression calculations. Unacceptable variables were removed from models in the order in which they were selected by the stepwise procedure, and the stepwise procedure repeated until a satisfactory model was obtained. Models modified in this way included those that contained variables which :

- had poor residual plots ;

- were expensive or difficult to measure ;

- were difficult to interpret. 
Tableau I : Variables relevées sur chaque site (n'incluant pas les variables "dérivées" - voir texte).

Table 1 : Variables recorded for each site (does not include 'derived' variables see text).

\section{General (recorded for whole site):}

percentage of water surface shaded by riparian vegetation

degree of substrate embededness

site accessibility for salmon and migratory trout

Recorded in detail for consecutive $10 \mathrm{~m}$ sections:

width (at section boundaries)

depth profile at section boundaries

\% abundance of different substrate classes:

- bedrock/artificial;

- boulders ( $>25.6 \mathrm{~cm})$;

- cobbles $(6.4-25.6 \mathrm{~cm})$;

- gravel/coarse sand $(0.2-6.4 \mathrm{~cm})$;

- fine sand/silt $(<0.2 \mathrm{~cm})$;

- compacted clay.

$\%$ abundance of different flow classes:

- cascade/torrential;

- glide/run (deep);

- glide/run (shallow);

- turbulent/broken (deep);

- turbulent/broken (shallow);

- slack (deep);

- slack (shallow).

$\%$ abundance of instream vegetation not providing cover:

- submerged macrophytes;

- emergent macrophytes;

- moss.

$\%$ abundance of vegetative cover for fish

- $>10 \mathrm{~cm}$

- $>20 \mathrm{~cm}$

\% abundance of non-vegetative instream cover ('submerged overhang'):

- bedrock, boulders \& cobbles;

- tree root systems;

- branches and logs;

- undercut banks;

- 'other' non vegetative. $\&$ cover from overhang within $0.5 \mathrm{~m}$ of the water surface

\section{General catchment features:}

distance from tidal limit

stream order

link number

link number of stream downstream of next confluence

site altitude

site gradient

stream flow

catchment area

mean conductivity

area of lakes and reservoirs within catchment

catchment gradient. 
Once a model was obtained where all variables were acceptable, variables were removed (starting with those selected first by the stepwise procedure) to see if any models with a better fit could be obtained.

Earlier work (MILNER et al., 1993) demonstrated the need to examine the contributions made by the different potential sources of variation to the overall variablity of the data-set. Techniques were devised to effectively 'partition' the variance in a data-set to allow the true variation due to spatial factors to be derived (see, for example, MILNER et al., 1993). In general terms, the spatial variance component is all that can be hoped to be accounted for by habitat models. Variance partitioning was applied to the models derived in the current study. This enabled the quality of the models to be expressed not only in terms of the amount of the overall variation accounted for (i.e. the $r^{2}$ value of the model), but also in terms of their success in explaining the spatial component of the observed variation. This latter statistic provided a far more realistic measure of the success of the modelling exercise, as it indicated the percentage of the variation which could be explained by spatial factors alone that the model had successfully accounted for.

It was originally intended to produce a set of predictive equations, and not to assess the nature of those independent variables found to be significant in the models derived during the development of HABSCORE. It was also not intended to determine the form of any potential causative relationships which may be in evidence. When interpreting the models derived from this work, significant habitat variables cannot be assumed to be having causative effects on salmonid density ; the contribution of each variable to the overall prediction is only relevant in the context of all other variables in the equation. Note that, as the models which were derived were intended for use as predictive tools, some independent variables were allowed to remain in the models despite not being being significant at the 0.05 level.

\section{RESULTS}

A brief summary of statistics relating to the five models is given in Table II, along with the results of the variance partitioning exercises which were undertaken on the data. The value for the spatial component of variance is given, along with the contribution made by random variation through time (represented by the 'interaction' term).

Tableau II : Qualité des modèles.

Table II : Model quality.

\begin{tabular}{rccccc}
\hline Parameter & Trout 0+ & Trout $<\mathbf{2 0 c m}$ & Trout $>\mathbf{2 0 c m}$ & Salmon 0+ & Salmon $>0+$ \\
\hline n (number of sites) & 520 & 554 & 282 & 178 & 202 \\
p (number of ind.variables) & 12 & 19 & 11 & 14 & 6 \\
$\mathbf{r}^{2}$ adj (\%) & $46.2 \%$ & $42.9 \%$ & $44.6 \%$ & $40.9 \%$ & $28.7 \%$
\end{tabular}

Sources of variance:

$\begin{array}{rrrcrr}\text { Spatial (explained) } & 46.2 \% & 42.9 \% & 44.6 \% & 40.9 \% & 28.7 \% \\ \text { Spatial (unexplained) } & 27.0 \% & 36.1 \% & - & 17.6 \% & 30.2 \% \\ \text { Interaction } & 26.3 \% & 20.6 \% & - & 40.7 \% & 40.4 \% \\ \text { Measurement } & 0.4 \% & 0.4 \% & 1.1 \% & 0.8 \% & 0.7 \% \\ & & & & & \\ \end{array}$

N.B.: \% Fit represents the percentage of the spatial component successfully accounted for by the model (see text for details). 
The independent variables used in the final models are listed in Table III, along with the transformation applied (were applicable). In addition, the sign (positive or negative) and significance of the regression coefficient for each variable in each model are given.
Tableau III : Variables utilisées dans les modèles, avec mention du signe et de la signification des coefficients de régression.

Table III : Variables used in National models, with sign and significance of regression coefficients.

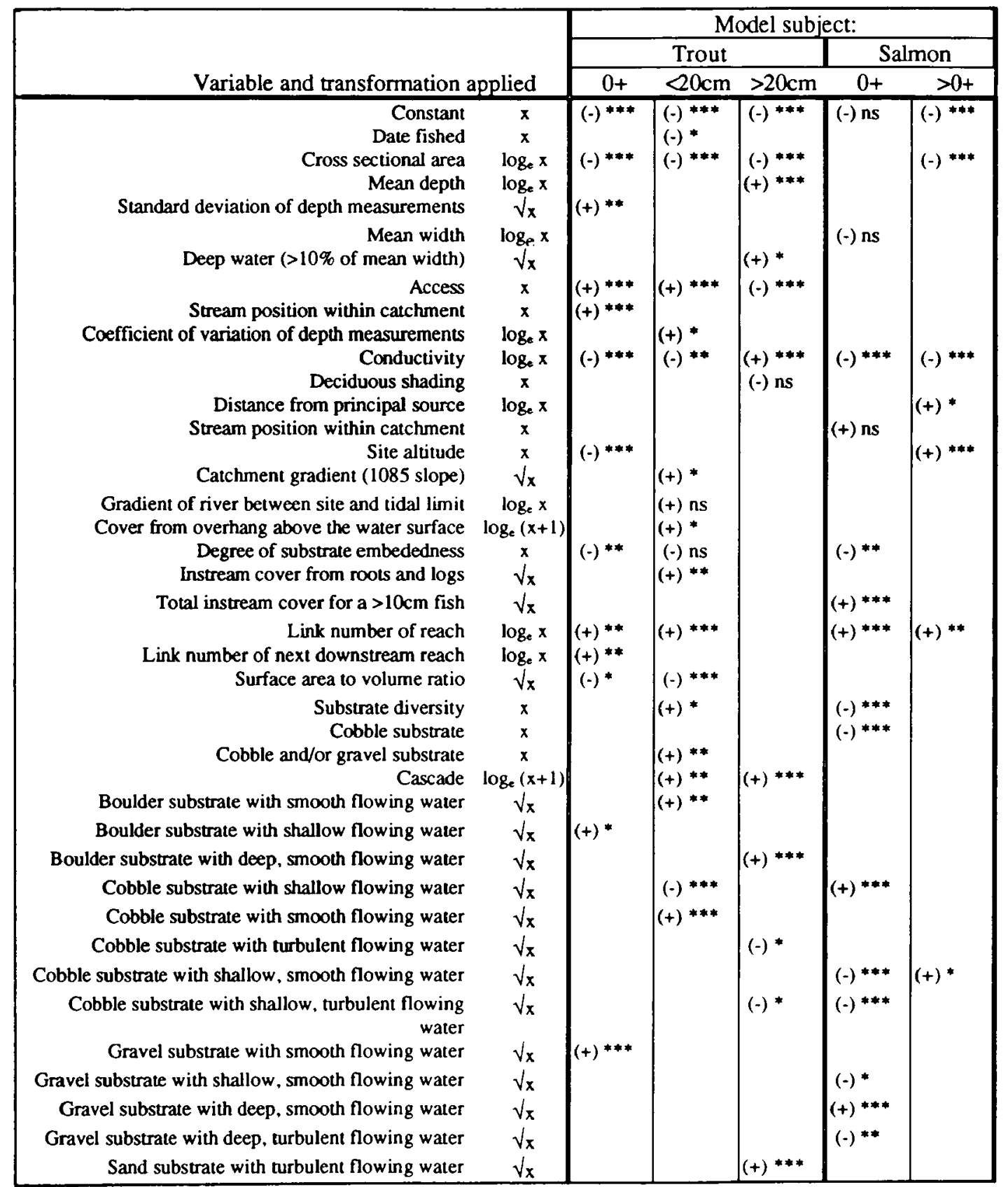

ns: $\mathrm{P}>0.05 ; \quad *: \mathrm{P}<0.05 ; \quad * *: \mathrm{P}<0.01 ; \quad * * *: \mathrm{P}<0.001$ 


\section{DISCUSSION}

\section{Model quality}

The $r^{2}$ coefficients vary across the models developed for the five categories of salmonid which were considered. In general terms, the models for salmon are poorer (i.e. have lower $r^{2}$ coefficients) than those for trout, suggesting that habitat variables are less able to account for the distribution of salmon than they are for trout.

It is interesting to note that the the $\mathrm{r}^{2}$ coefficients for both salmon models from the earlier version of HABCSORE $\left(48.3 \%\right.$ for $0^{+}$salmon and $26.2 \%$ for $>0^{+}$salmon) were similar to the $r^{2}$ values for the models detailed in this paper (Table II). This suggests that there is no decrease in the ability of habitat-based empirical models to account for the spatial variability of the salmon populations when moving from a regional to a national scale.

In contrast to this, the models for trout produced from the full national data-set have a reduced predictive power compared to the original Welsh models. Values for the $r^{2}$ coefficient for $0^{+}$and $>0^{+}$trout for the original Welsh models were $72.3 \%$ and $66.2 \%$ respectively, compared to $r^{2}$ values in the range $43-46 \%$ (see Table II). It is likely that this is a result of the inclusion of a wider range of habitat types national data-set (e.g. chalk streams and other lowland trout fisheries) compared to the relatively restricted range of upland streams used to derive the original Welsh models.

The variance partitioning exercise which was applied to the National data-set (see Table II) provides an indication of the likely limit to the quality of any empirical models derived from spatial (i.e. habitat) data. For $0^{+}$trout, $46.2 \%$ of the overall variability of the data was successfully explained by the model. However, the spatial variance component represented only $73.2 \%$ of the total variability of the data, a value which effectively represents the maximum $\mathrm{r}^{2}$ value that could be hoped to be achieved by using spatial models. Consequently, the model can be said to have a success of $63.1 \%$ (i.e. 46.2 as a percentage of the maximum attainable, 73.2) - a statistic which is termed the \%Fit in Table II. Unfortunately, because of the lack of historical data with which to ascertain the contribution of temporal factors to the overall variability of the data, it has not been possible to apply the variance partitioning exercise to the data for trout $>20 \mathrm{~cm}$. The values for the total spatial component of variability for each of the models (i.e. the sums of the 'Spatial [explained]' and the 'Spatial [unexplained]' terms for each of the models in Table II) cover the range $58.9 \%\left(>0^{+}\right.$salmon) to $79.0 \%\left(>0^{+}\right.$trout $\left.<20 \mathrm{~cm}\right)$. It is these values that demarcate the probable limits of success of habitat models of this type.

The fact that the measurement error component of the overall variance is low in all of the models (Table II) implies that the random error in the fish population estimates which were used was low, at least in relation to the random errors associated with the measurement of habitat variables.

As has already been stated, it was not intended to discuss the nature of the variables which were found to be significant in the models derived in the course of the development of HABSCORE. However, to permit comparison with other models, the variables used are listed in Table III. In addition to the nature of each variable, the sign and significance of the associated regression coefficient are given.

\section{Model outputs}

A series of macro-driven spreadsheet programs have been produced which will allow site habitat and catchment features to be entered, and which will execute the models in order to derive the expected population densities for the site.

The expected density of fish of a given species and age/size grouping at a site is termed the Habitat Quality Score (HQS). The HQS is effectively a measure of the habitat quality in terms of the salmonid density expected under clean water conditions. In addition, confidence limits for the HQS can be derived, and these are provided by spreadsheet programs. 
Note that, whilst the model is capable of predicting HQS values for sites whose nature is different to those used to develop the models (i.e. the model can be used to extrapolate to beyond the range of the independent variables used in the original regression analyses), results obtained from such use would need to be interpreted with care. The software which runs the models highlights those habitat features of a new site which make it atypical of the set of sites originally employed in model construction; it is the responsibility of the potential user to assess the implications of such extrapolation(s) and interpret the results as appropriate.

Comparison of the HQS values with actual observed values are made through the use of the Habitat Utilisation Index (HUI). Values for the HUI are provided by the spreadsheet, and are calculated as the ratio of the log value of the observed density to the log value of the HQS.

A HUI value of unity will therefore indicate that the observed population is equal to the expected (HQS) value. HUI values of less than one indicate that the site is not performing as well as sites of a similar habitat type that were originally used to develop the models, whilst HUI values in excess of one suggest that the site is behaving better than sites of a similar habitat type in the original data-base.

\section{Applications}

The models which have been developed have several fisheries management applications, including :

- the assessment of fishery performance ;

- environmental impact detection ;

- environmental impact assessment ;

- stream classification ;

- assessmeht of fisheries potential.

\section{Fishery performance}

The relationship between observed and expected populations (as represented by the HUI value) provides an indication of the degree to which a site is currently attaining its potential, whilst taking account of the effect of habitat. Although the performance of a single site can be reported in this way, the $\mathrm{HUI}$ is of greater value when comparing performance between-sites. As the HUl effectively accounts for the effects of habitat, direct comparisons of performance can be made between sites, despite any apparent differences in habitat quality.

\section{Environmental impact detection}

The derivation of the HUl (i.e. the comparison of observed with expected population densities) provides a measure of the performance of a site relative to the quality of those sites used to develop the models. As the HABSCORE models were derived from data pertaining to unimpacted sites, deviation from the expected performance level can be used as an indication of a likely environmental impact.

\section{Environmental impact assessment}

The expected salmonid population densities for each species/age group (i.e. the HQS values) are those expected under conditions were only habitat is potentially limiting, and can consequently be regarded as indices of habitat quality. As such, HQS estimates for new sites can be used to account for habitat differences when making between-site comparisons of salmonid populations.

For example, where fish population data from sites suspected of being impacted (e.g. sites downstream of a suspected polluting discharge) is to be compared against population data from un-impacted sites (e.g. sites upstream of the discharge) HQS values can be used as co-variates in an analysis of co-variance, in order to take the potential effects of habitat into account. 


\section{Stream classification}

Salmonid population predictive models such as HABSCORE can be used as the basis of a fishery classification system in two distinct ways. Firstly, HQS values provide a means whereby sites can be classified according to their habitat quality. This would effectively be a classification based on the potential maximum salmonid populations that could be attained given that no limiting factors other than habitat are operating.

Alternatively, a classification based upon the relative performance of sites (in terms of the HUI) would put the current standard of a site into perspective, and would allow sites which are performing poorly, relative to their potential, to be identified. This would represent a much refined version of existing classification systems (e.g. MAINSTONE et al., 1994).

The wide geographical basis of the newly developed HABSCORE increases the applicability of any classification system which is based upon either HQS or HUI values, so facilitating the use of such systems throughout the NRA.

\section{Fisheries potential}

In addition to providing a benchmark against which salmonid stocks may be assessed, HQS values from HABSCORE allow the potential carrying capacity for migratory salmonids to be assessed for currently inaccessable sites. Such information would be of value in any cost-benefit analysis relating to proposed work to open-up such sites (e.g. through the installation of fish passes at otherwise impassable falls).

\section{General}

There is a wide range of factors that can be used to describe stream habitat. These basically break down into the local physico-chemical and biological features of a given stream site (e.g. channel form, dimensions, bankside and instream cover, temperature, food availability, etc.), and the larger-scale catchment attributes such as geomorphology, topography, land-use and climate (MILNER et al., 1985). However, it is not possible to consider site and catchment features in isolation from one another in schemes of habitat evaluation. The contributions of these sources need to be considered together, and the continuum of change of these factors along a given catchment should be recognized (HUET, 1959). The use of a wide range of variables during the modelling phase (i.e. permitting the modelling procedure to select from the whole array of site and catchment features) and the specific regression techniques used were seen as means of effectively reconciling this requirement.

It has been suggested that habitat needs may alter with the life-stage, size and species concerned (MILNER et al., 1981 ; KENNEDY and STRANGE, 1982 ; MORANTZ et al., 1987). It is likely, therefore, that the derivation of successful models may, in part, be a result of their specificity. The production of five separate models represents a compromise between this apparent need for highly subject-specific models and the pragmatic approach demanded of a potential management tool.

The survey techniques used to collect the required information to use the HABSCORE system have been refined and closely defined survey routines and associated field manuals have been produced to facilitate the use of the HABSCORE survey technique throughout England and Wales.

\section{REFERENCES}

BARNARD S., 1992. HABSCORE development. Report to NRA No. 338/3/W, $109 \mathrm{p}$.

CARLE L., STRUB M.R., 1978. A new method for estimating population size from removal data. Biometrics, 34, 621-630.

FAUSCH K.D., HAWKES C.L., PARSONS M.G., 1988. Models that predict the standing crop of stream fish from habitat variables: 1950-85. General Technical Report, PNWGTR-213, Portland, OR: US Department of Agriculture, Forest Service, 52 p. 
HUET M., 1959. Profiles and biology of Western European streams as related to fish management. Transactions of the American Fisheries Society, 88, 155-163.

KENNEDY C.G.A., STRANGE C.D., 1982. The distribution of salmonids in upland streams in relation to depth and gradient. Journal of Fish Biology, 20, 579-591.

MAINSTONE C.P., BARNARD S., WYATT R.J., 1994. Development of a fisheries classification scheme. Report to NRA No. 244/7/Y, 220 p.

MCCULLAGH P., NELDER J.A., 1989. Generalised Linear Models. Monographs on Statistics and Applied Probability, 37. Chapman and Hall, $511 \mathrm{p}$.

MCFADDEN J.T., COOPER E.L., 1962. An ecological comparison of six populations of brown trout (Salmo trutta). Transactions of the American Fisheries Society, 91, 53-62.

MILNER N.J., HEMSWORTH R.J., JONES B.E., 1985. Habitat evaluation as a fisheries management tool. Journal of Fish Biology, 27 (Suppl. A), 85-108.

MILNER N.J., WYATT R.J., SCOTT M.D., 1993. Variability in the distribution and abundance of stream salmonids, and the associated use of habitat models. Journal of Fish Biology, 43 (Suppl. A), 103-119.

MILNER N.J., SCULLION J., CARLING P.A., CRISP D.T., 1981. The effects of discharge on sediment dynamics and consequent effects on invertebrates and salmonids in upland rivers. In : Advances in Applied Biology, Croaker T.H. (ed.), 154-220. Acedemic Press : London.

MORANTZ D.L., SWEENEY R.K., SHIRVELL C.S., LONGARD D.A., 1987. Selection of microhabitat in summer by juvenile Atlantic salmon (Salmo salar). Canadian Journal of Fisheries and Aquatic Sciences, 44, 120-129.

NRA, 1991. HABSCORE software manual (Version 2.1). NRA, 28 p.

POCOCK S.J., COOK D.G., BERESFORD S.A.A., 1981. Regression of area mortality weights on explanatory variables: what weighting is appropriate? Applied Statistics, 30, 286-295.

WINSTONE A.J., 1993. Juvenile salmon stock assessment and monitoring by the National Rivers Authority - a review. In : Production of juvenile Atlantic salmon, Salmo salar, in natural waters, Gibson R.J. and Cutting R.E. (eds.), 123-126. Canadian Special Publication on Fisheries and Aquatic Sciences, 118. 